\title{
The Tourism Development in Uzbekistan: An Assessment
}

\author{
Adham Israilov ${ }^{1}$, Asterio T. Miranda, Jr. Ph.D ${ }^{2 *}$, Juneth Lourdes F. Miranda, CPA, D.M ${ }^{3}$ \\ ${ }^{1}$ Instructor. Yeoju Technical Institute in Tashkent, Tashkent City Uzbekistan. \\ ${ }^{2}$ Associate Professor. Department of Taxation, College of Business Administration, Keimyung \\ University. Daegu City, Republic of Korea. \\ ${ }^{3}$ Associate Professor. Keimyung Adams College (KAC), Keimyung University, Daegu City, Republic \\ of Korea.
}

*Corresponding Author: Asterio T. Miranda, Jr. Ph.D, Associate Professor. Department of Taxation, College of Business Administration, Keimyung University. Daegu City, Republic of Korea

\begin{abstract}
This study endeavored to assess the quality of tourism development in Uzbekistan, particularly in the 3 cities of Samarkand, Khiva and Bukhara. Specifically, this investigation determined the demographic profile of the respondents; determined the level of perceptions among respondents on their assessment regarding the quality of tourism development in Uzbekistan; and determined whether a relationship existed between the demographic profile of the respondents and their level of perception on the quality of tourism development in Uzbekistan.
\end{abstract}

This study is descriptive and correlational, which utilized survey questionnaire to derive data from the actual respondents. The researcher used convenience sampling in view of the very huge population. The respondents were drawn through quota sampling, which targeted a total of 100 respondents: 34 from Samarkand City; 33 from Bukhara City; and 33 from Khiva City. For the actual respondents, only 97 however participated in this study. The researcher had been constrained by the lack of time to look for other 2 respondents from Samarkand City, and another 1 from Khiva City, but Bukhara City had 100 percent retrieval rate, which means, the number of 33 cooperated in the survey. The data gathered with respect to the demographic profile of the respondents have been treated through the use of simple frequency counts and percentages. While the assessment on the level of perception on the quality of tourism development in Uzbekistan, weighted mean had been used. In terms of finding out the relation amidst the demographic profile of the respondents and the level of perception on the quality of tourism development in Uzbekistan, SPSS software had been used.

The findings in terms of the respondents` demographic profile, majority of them belonged to 45 to 64 age bracket, with 15 years old as the youngest and 66 years old as the oldest. Majority of the respondents are males, mostly Russians, Indians and Japanese. Most of the respondents are college graduates, with annual income ranging from US\$10,000 to 19,000; and preferred to stay for one week whenever they visit Uzbekistan for leisure purposes. Most of the respondents are first timers in Uzbekistan, and they were motivated to visit the country in view of the many tour activities being offered. The respondents claimed that the source of information that prompted them to visit Uzbekistan came from the travel agencies and tour operators.

As regards assessment made by the respondents on the level of perception on the quality of tourism development in Uzbekistan, the result revealed as generally good (grand mean of 3.59). However, the assessment further pointed out that the kind of transportation facilities being provided to the tourists visiting Uzbekistan is a concern that the government of Uzbekistan should give relevant focus. Night life as most of activities that tourists would want to have during their visit, is also another concern that need to be addressed to.

In finding out whether a compelling relation existed amidst the demographic profile of the respondents and their level of perception on the quality of tourism development in Uzbekistan, with the significance level of 0.05 , the chi square test disclosed that the age, gender, nationality, staying period, visiting purpose, frequency of visit, source of information, motivation are significantly related, while education, income and price are not.

Keywords: Tourism, Tourism Development, Assessment, Demographic profile, Level of perception

\section{BACKGROUND OF STUDY}

Every field of social, political, and financial activity is up to contribute to the economy of a particular country, and one of them is tourism industry. The tourism industry being a relevant dimension in the 
socio-economic aspects of development of the statecan be significantly big in terms of international trade, entrepreneurship, foreign investment, creation of new jobs for workforce as well as protection of cultural and natural heritage.

In Uzbekistan, tourism is regarded as one of the most promising industries. But it is not however, free from limitations and problems. There are possible problems that the industry is facing, whether it could be in the management, or the pressing issue on political reformations, and some other financial constraints. In fact, the President of Uzbekistan pointed out several factors to develop the economy of the Republic, and one of them was the sector of tourism. Along this vein, he issued a Presidential Decree entitled 'The Measures to ensure the rapid development of tourism in The Republic of Uzbekistan(World Scientific News, 2017). The decree put emphasis towards introducing to people the country`s economic strategies and programs that are potentialfactors thatwill advance life quality of the population of Uzbekistan, and may initiate new steps in the development of the tourism sector in Uzbekistan.

The industry of tourism is growing fast and became one of the significant spheres in this century (Agnew, M.D. and Viner D., 2001).The industry characterizesmassive and complex interaction of people, who demand a wide range of services and facilities, and inputs_Price V. and Tewksbury D. (1997). Having diverse sections, the development of tourism is comprehended and accepted as one of the vital sections of economic progress and valuable part, specifically in developing countries.

In the course of recent decades, the tourism industry has been relentlessly expanding beyond the significance of the tourism business to the extent of social and financial improvement of numerous states. Nowadays, the business capacity of this industry squares with or even surpasses the trade of oil, foodstuff or automobile in terms of business capacity . The industry of tourism evolved into a considerable component throughout the world market , and speaks to meanwhile particular pay off source for some progressing states $(\mathrm{Xu}, 2013)$.

Subsequent to the segregation of the Former Soviet Union in 1991, the previous Soviet countries, namely, Kazakhstan, Kyrgyzstan, Tajikistan, Turkmenistan, and Uzbekistan, demonstrate vital chances to end up a noteworthy tourism spots in terms of social, chronicled, archaeological, and common attractions. In the wake of getting to be free, the strategy and model of the travel industry advancement in these nations was principally founded on enhancing the tourism industry (Coulibaly, et. al., 2012).

Concurrently with the independence, the industry of tourism became peculiar part of developing and substantial fields of business, in addition to that, a focus that has reached to the extent of importance in social and financial life of the country. It ought to be pointed that within two years of independence there have been solely four companies which were related to the industry of tourism in developing Uzbekistan, contrasting to the current time. According to United Nations World Tourism Organization ( 2013) there are 800 touristic corporations and lodgings private sector of tourism industry, together with five hundred hotels with total volume of thirty thousand of places and roughly 300 tour operators and 40 agents.

Perfectly situated world heritage borders of the Former Soviet Union Countries, Uzbekistan makes the spot charming, thus, attracting guestscoming from other countries. Moreover, one significant aspect is the geographical location of the country as it was a spot where people could make commerce, and the reason why it was famous throughout the world was its position across the straightest commerce course connecting China to Europe, the Silk Road established by the Roman Empire (Kantarci,et.al., 2014).States of the Former Soviet Union such as Kazakhstan , Kyrgyzstan, Turkmenistan, Uzbekistan, and Tajikistan cover a spectacular and rich available tourism interest that has excessive potential to form diverse category of rare activities (Horák, 2014).

Further development of tourism industry in Uzbekistan is geared towards increasing its role in financial and economic system, and supply the society with jobs, assert the continuation inevitably in wide selection analysis of tourism industry promoting services, and develop good scientific researches that produce the premise for the promotion of prospective programs.

It is on the light of the foregoing issues that prompted the researcher to conduct a scientific investigation that will bring into the fore the tourism development in Uzbekistan. It will purposely assess the quality of tourism development, hence the findings may strengthen the further advancement 
of the industry focusing on the areas or aspects of tourism that need more programs, policy directions towards improvement.

\section{Objectives of the Study}

This study endeavored to assess the quality of the tourism development in Uzbekistan. Specifically, it tried to achieve the following objectives:

1. To determine the demographic profile of the respondents in terms of age, sex, nationality, educational attainment, income level, length of stay, purpose of visit, frequency of visit, knowledge about tourism in Uzbekistan, and motivation to visit.

2. To find out the level of quality of the tourism development in Uzbekistan based on the assessment of the respondents on the following attributes, namely: museum, architecture,Climate, Natural attraction, Tours/excursions, Transportation, Tourist information, Accommodation, Hospitality, Restaurant, Bar and Café, Night life, Cleanliness, Uncrowdedness, Shopping facility, Accessibility, Safety, and Price.

3. To determine whether a significant relationship exist between the demographic profile of the respondents and the perception on level of quality of the tourism development in Uzbekistan.

\section{Limitations of the Study}

This research delved into assessing the quality of the tourism development in Uzbekistan focusing in the three (3) cities of Samarkand, Bukhara, and Khiva. The researcher derived data solely from the 97 out of the 100 target respondents. The respondents are the tourists from the 3 mentioned cities, and were available in the area at the time the researcher conducted the survey. Convenience sampling was employed by the researchers using the quota sampling technique in view of the huge number of the population. The researchers confined their study respondents on foreign visitors or tourists, and did not involve any local tourists in the study. Hence, all respondents are foreigners and not residents of Uzbekistan.

With respect to the instrument used in the study specifically on the indicators or attributes to assess the quality of the tourism development of Uzbekistan, the researchers adopted the survey instrument of Marino (2008). There were few modifications made by the researcher on the words used to label the indicator or attribute, but they did not affect their meanings. The researcher did not anymore opted to subject the instrument for validation as it has already been adopted in the aforementioned study.

\section{Theoretical Framework}

This study was based on Expectancy theory first proposed by Vroom (1964). According to this theory customers (tourists in the case of this study) will be motivated to select a certain behavior (visiting Uzbekistan) if they have high expectations of it. For this study the researcher considered that tourists would be inclined to visit Uzbekistan if they expect a certain destination image and tourist satisfaction.

Conforming to Expectancy theory, people have beliefs that their efforts will have returns, in this research tourists have certain expectations of Uzbekistan tourism industry when they intend to visit the country and they expect return such as good service quality and/or to experience astonishing tourist spots. The other supposition is that when people consider their effort and compare it with the result they obtain. In this case, tourists compare their effort of visiting Uzbekistan and the experience they acquired in Uzbekistan. Through this theory, the researcher gained tourist perception about quality of developing tourism industry in the state.

\section{Conceptual Framework}

This study is geared towards assessing the level of perception on the quality of tourism development in Uzbekistan. It will specifically assess whether the tourism development is very good, good, moderate, poor or very poor quality. Likewise, this study also determined the demographic profile of the respondents in terms of age, sex, nationality, educational attainment, income level, length of stay, purpose of visit, frequency of visit, knowledge about tourism development, motivation to visit and find out whether the demographic profile of the respondent is significantly related to the level of perception on the quality of tourism development in Uzbekistan. 
INDEPENDENT VARIABLES

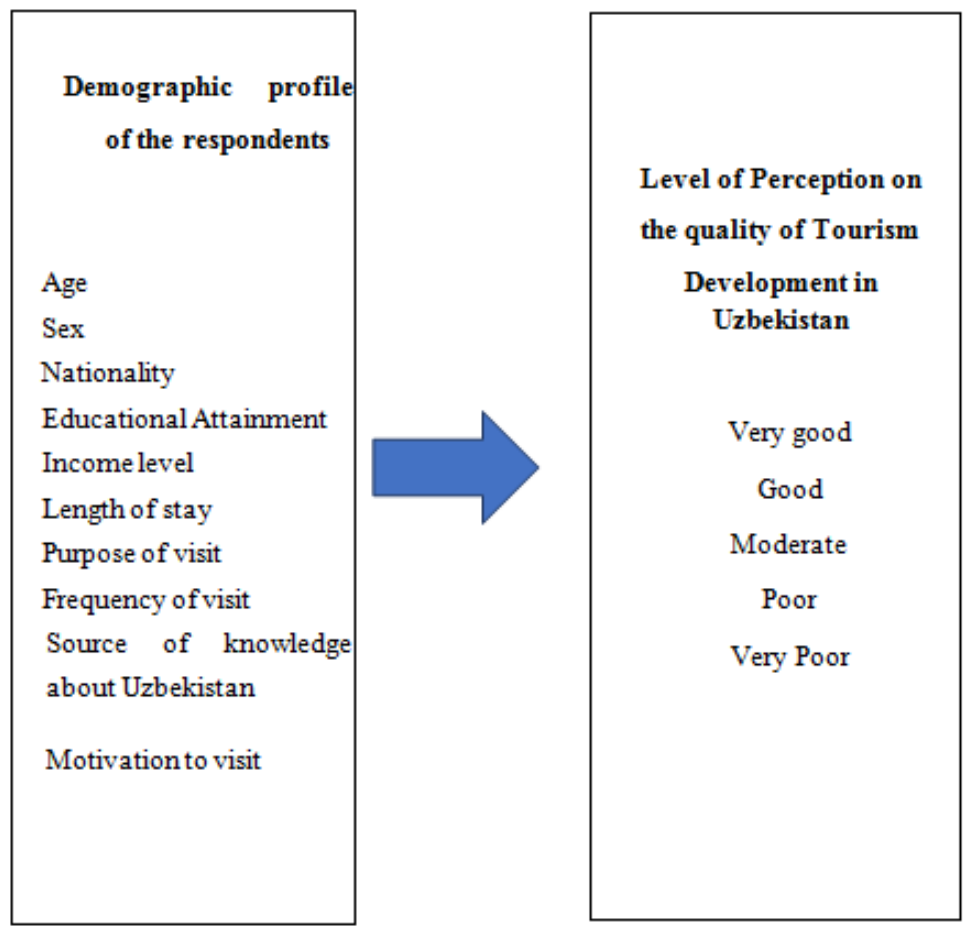

Figure 1-1. Paradigm. Schematic diagram presenting the relationship of independent and dependent variables of the study.

\section{Hypothesis.}

The conceptual framework as presented tried to bring into fore the presumed relationship of the following:

H 1:The demographic profile of the respondents has significant effect on the level of perception on the quality of tourism development in Uzbekistan. The sub-hypotheses tested if significant relationship exists or not, are presented below:

$\mathrm{H} \mathrm{1-1:Age} \mathrm{of} \mathrm{the} \mathrm{respondent} \mathrm{is} \mathrm{significantly} \mathrm{related} \mathrm{to} \mathrm{the} \mathrm{level} \mathrm{of} \mathrm{perception} \mathrm{on} \mathrm{the} \mathrm{quality} \mathrm{of} \mathrm{tourism}$ development in Uzbekistan.

$\mathrm{H} \mathrm{1-2:} \mathrm{Gender} \mathrm{of} \mathrm{the} \mathrm{respondent} \mathrm{is} \mathrm{significantly} \mathrm{related} \mathrm{to} \mathrm{the} \mathrm{level} \mathrm{of} \mathrm{perception} \mathrm{on} \mathrm{the} \mathrm{quality} \mathrm{of}$ tourism development in Uzbekistan.

H 1-3: Nationality of the respondent is significantly related to the level of perception on the quality of tourism development in Uzbekistan.

H 1-4: Educational attainment of the respondent is significantly related to the level of perception on the quality of tourism development in Uzbekistan.

$\mathrm{H} \mathrm{1-5:Income} \mathrm{level} \mathrm{of} \mathrm{the} \mathrm{respondent} \mathrm{is} \mathrm{significantly} \mathrm{related} \mathrm{to} \mathrm{the} \mathrm{level} \mathrm{of} \mathrm{perception} \mathrm{on} \mathrm{the} \mathrm{quality}$ of tourism development in Uzbekistan.

H 1-6: Length of stay of the respondent is significantly related to the level of perception on the quality of tourism development in Uzbekistan.

$\mathrm{H}$ 1-7: Purpose of visit of the respondent is significantly related to the level of perception on the quality of tourism development in Uzbekistan.

H 1-8: Frequency of visit of the respondent is significantly related to the level of perception on the quality of tourism development in Uzbekistan.

H 1-9: Source of knowledge about Uzbekistan of the respondent is significantly related to the level of perception on the quality of tourism development in Uzbekistan. 
H 1-10: Motivation to visit of the respondent is significantly related to the level of perception on the quality of tourism development in Uzbekistan.

\section{Related Literature and Studies}

\section{Tourism in Uzbekistan}

The industry of tourism was not considered as a significant factor contributing to the economic development of Uzbekistan. Nevertheless, considering the geographic position of the country and resources of tourism, it was seen that the industry could be important contributing component towards economicdevelopment (Golisheva , 2012).

Since gaining its sovereignty in 1991, Uzbekistan started to construct and re-organize its infrastructure of the industry. The initial stage related to the issues of tourism industry was establishment of National Committee 'Uzbektourism' which is the leading body in terms of controlling tourism activities throughout the country. The Committee provides all the needed changes and modernizations to the industry in the area of Uzbekistan. After the foundation of the Committee, the country has been reforming its local air fleet and roads. Tax exemptions were installed and the system of taking tourist activity licenses were modernized. The private and government-controlled companies, which provide tourist services, were exempted from paying VAT (Value Added Tax). These factors contributed to a significant growth in the tourism sector of Uzbekistan.

The geographic location along the Great Silk Road provides the growth in the number of international arrivals. Furthermore, rich heritage of culture, ancient traditions and history draw attention among tourists who are interested in the sphere of religion, culture, archeology and ethnography. Uzbekistan has valuable spots of Islam, Christianity and Buddhism, which provides the development of pilgrimage tourism. Moreover, access to attractive natural spots (mountains, desserts, lakes,) can be considered a remarkable factor in the way of the advancement of adventure and eco-tourism. Nevertheless, only 5-8\% part of natural and cultural heritage is used for tourism activities which indicates that the potential of tourism is not fully used. (Golisheva ,2012)

Introducing Uzbekistan into the market of global tourism, the agenciesinvolved in the tourism industry use the link of Uzbekistan and Silk Road. The agencies provide information of culture, architecture and ancient history and alongside with above mentioned components of the industry, hiking, natural reserves, less-known spots have been promoted as well, with the helicopter tours from 2018.

The international channel 'Euronews' held an advertising campaign in 2013 which was devoted to the economic and investment field. Before airing the prime time programs, promotional-advertisement video dubbed as "Welcome to Uzbekistan" in Russian and English languages have been aired three times a day from October to December in 2013, featuring the Silk Road spots in Uzbekistan Samarkand, Bukhara and Khiva. This factor, also triggers the growth of international visits in Uzbekistan.

\section{Tourism contribution to the GDP of Uzbekistan}

In 2008 for the first time the quantity of travelers achieved a million, and the succeeding year after recorded biggest number of travelers during past 18 years, which soared-up by $13.6 \%$ comparing to that of 2008. For the past severalyears, travelers' entries in average is over a million yearly. The direct contribution of Travel \& Tourism to GDP in 2017 was posted about $0.9 \%$ of GDP. This primarily reflects not only the economic activity generated by industries such as hotels, travel agents, airlines and other passenger transportation services (excluding commuter services). But it also includes, for example, the activities of the restaurant and leisure industries directly supported by tourists (World Tourism and Travel Council, 2018).

The effects of economic influence analysis for Uzbekistan showed that direct contribution of Tourism industry in terms of GDP was US\$ 0.463 billion in 2012, which was respectively equal to a contribution of 1 per cent of Uzbekistan's GDP and inferred that Uzbek travelers' segment directly promoted 110.000 occupations, demonstrating 0.8 per cent of overall employment in Uzbekistan. The direct contribution to Travel \& Tourism is estimate to increase by 5.6\% p.a., from 2014 to 2023, to US\$ 0.812 billion ( $0.8 \%$ of GDP) in 2023 (in constant 2012 costs). By 2023, Travel \& Tourism will represent for 151,000 employments directly, a growth of $3.4 \%$ p.a. over the following decade. Taking 
into account supply chain influences and the effect of capital share and cooperative government spending on behalf of tourism economy industry, the broader Travel \& Tourism economy measured the general influence of tourism economy sector in Uzbekistan represented US\$1,485 billion in 2012 (3.1\% of Uzbekistan's GDP) and 361,400 occupations (2.6 per cent of whole employment in Uzbekistan) in 2012. The overall contribution of Travel \& Tourism is predicted to raise by $5.8 \%$ p.a. to US\$ 2,696 billion by 2023 (2.8\% of GDP). By 2023, Travel \& Tourism is estimated to form 510,000 workplaces (2.4\% of total occupation), a growth of $3.5 \%$ pa over the period. The direct contribution of Travel \& Tourism to GDP is expected to grow by $6.0 \%$ p.a. to UZS4, $155.4 \mathrm{bn}(0.9 \%$ of GDP) by 2028. (World Tourism and Travel Council. Economic Impact 2018).

\section{Related Studies}

Tourism is an asset which is positioned on concurrent production and consumption. The development of tourism deals with all the activities related to providing convenience for international visitors being in a touristic spot. The development concerns as well as skills advancement, employment and revenue growth along with marketing. Management of diverse tourist destinations by way of intermediary, guiding and consultation of territorial touristic companies promotes the development of tourism. As the concept of development of tourism being understood, it can be deduced that the development of tourism and importance of that has influence on growing countries, precisely, financial and economic progress of them. (Ateljevic\& Page, 2009)

Indeed, the industry of tourism is generating at a quicker pace worldwide and a lot more states intend to inspire ideas related to the need of forming the industry of tourism for financial and economical points of interest. As per the United Nations World Tourism Organization in 2006, the travel industry has developed, precisely, touristic spots there has been a far-reaching increment in the land extension of the tourism industry all through the globe which has made it feasible for developing countries to form the tourism industry at their own pace for their financial advancement. Nevertheless, it is a general phenomenon that tourism industry vitally affects the community, geology, condition and economic life of any society. As for the people of a country, the fast improvement of the industry of tourism is the capability that brings society out from the curve of unemployment. The industry offers space for cooperation and companies inside the tourism industry business are in this way growing as well as prospering and achieving financial movement (Morrison, Rimmington\& Williams, 1999).

In estimating the improvement of a country certain factual files are mulled over which incorporates income per capita, (GDP), average of life length, and literacy rate.

Countries that are developing, by and large, are communities which have not accomplished all the steps in terms of industrialization with respect to regional populaces, and there exists, as a rule, a medium to low expectation for everyday life. Developing countries are looked with low salary and high populace development. As a rule, improvement involves an advanced foundation (both institutional and physical) above all occupying from horticulture. The travel industry as a segment can realize the fundamental improvement required for a fast development of financial and economiclife of those growing countries (Godfrey and Clarke, 2000).

The improvement of one particular state is estimated based on some statistics, for instance, income per capita (GDP), expectancy, the rate of proficiency (disregarding perusing compulsion). The United Nations Organization set up the Human Development Index (HDI), the complex of standards of the mentioned insights, aiming measurement for the dimension of human advancement for states where information can be accessible (Godfrey \& Clarke, 2000). Countries that are developing are, as a rule, communities which have not accomplished all the steps in terms of industrialization with respect to regional populaces, and there exists, as a rule, a medium to low expectation for daily life.

A few investigations estimated alterations in terms of the image of destination with the help of contrasting expected and experienced images, affirming the fact a genuine appearance adds diversity in terms of the image of destination (Phelps 1986, Chon 1991, Fakeye\& Crompton, 1991).

An example of such researches was conducted among voyagers from South Korea visiting Central Asia such as Uzbekistan, Tajikistan, Kazakhstan, Kyrgyzstan and Turkmenistan (Kantarchi, 2007). By looking at expected images about Central Asia and advantage acquired from the movement (desire) with experienced images so advantages got (genuine encounters), the investigation disclosed that several expected images of the area and advantages looked for were necessarily not quite the same as 
post-travel images. Exceptionally, visitors grew a decent full of post-travel image of Central Asia after that venture. Adjustments in terms of intellectual image of the area were noted, be that as it may, to another degree (Lee, et. al., 2012). Adjusted instigated perception happens to be the aftereffect of individual practice in the destination that happen to be the final step of the model.

The Development of tourism as a process. The advancement of the tourism industry is to a great extent ordered by production of essential foundations in the host community. The tourism industry improvement includes careful planning, organization, and management. The perfect of creating the tourism industry in a locale depends on the foundations that are set up. This facility achieves the advancement of the tourism industry in the locale. The nearness of good facility enhances economic effect of the tourism industry on the host community, having as a top priority that community is the central point to present day the tourism industry (Godfrey and Clarke, 2000).

Nevertheless, communities were the essential component in the supply of settlement, transport offices and administrations. As the patterns go on, the inflow of traveler will be on the expansion, in this way making the road for in organizations and eateries. As the procedure of advancement proceeds with, the legislature and private speculators would be urged to put more in the tourism industry. The collaboration of the administration and private financial specialists would realize the making of diversions parks, entertainment meccas, and different offices that can convey much enhancement to the improvement of the tourism industry.

As it was referenced above, the tourism industry is a quickly developing industry on the planet. It has turned out to be possibly critical for a few countries as their significant wellspring of pay. Aside from being a financial spine of a few countries, it likewise helps in the public activity of the host communities. In developed countries, for example, France and Spain, the tourism industry has contributed monstrously to the development of the country. In the most recent decade, Tourism has assumed an inexorably significant job in the economic improvement of numerous countries. The development has been driven by an expansion sought after and in the exertion of the supply destinations. In that capacity, interest for the tourism industry is an essential component in the tourism industry framework. The dimension of the tourism industry request has achieved a surprising dimension in the new thousand years in this way giving the tourism industry and other the tourism industry partners an incredible test (Godfrey and Clarke, 2000).

Hospitality Service in Tourism Development .The most pivotal source of developing tourism is through different ways the hosts offer their service. The service we offer could be different including openness, gentility, good organization. Then we have to facilitate those services with the right and appropriate conditions housing, food and leisure facilities for the expected tourists. (Zabkaret al., 2010; Gallarza et al., 2013; Ramseook-Munhurrun et al., 2015). People tend to categorize their destination in terms of how the elements mentioned above are organized. (Zabkaret al., 2010). The opinions of tourists are affected by the places they visit as they experience new facilities and attractions. Moreover, the accessibility to those places has a huge influence on the tourists' perceptions on choices. (Chen \& Tsai, 2007; Al-Ababneh, 2013).

Customer satisfaction. We can find a lot of researchers who studied the Customer satisfaction in the world wide tourism and hospitality. The main reason is clearly known that it results in good continuation opening a broad way to the business (Kozak, 2001; Gursoy et al., 2007; Chen \& Tsai, 2007). Many agendas and models have been established to describe satisfaction. A couple of those models could be the expectation-disconfirmation paradigm and the equity theory (Jang \& Feng, 2007). There can be various explanations of customer satisfaction. However, grading process is considered to be the most important part identifying customer satisfaction according to the general agreement of researchers. (Pizam\& Ellis, 1999; Ryu, Han \& Kim, 2008). Tourist satisfaction can be learned by those who are part of touristic facilities and they are responsible to give their estimation over those destinations and their services (Salleh, Omar \&Yaakop, 2013).

Many studies confirmed that if the tourists are content and their satisfaction is as expected, they tend to be loyal for the destinations (Kozak\&Remmington, 2000;Kozak, 2001; Yoon \&Uysal, 2005; Prayag, 2009; Ramseook-Munhurrun et al., 2015).

Economic impacts of tourism. The tourism industry financial advantages are touted by the business for an assortment of reasons. The tourism industry organizations depend broadly on one another and 
in addition different organizations, government, and inhabitants of the neighborhood community. Financial advantages of the tourism industry will reach for all intents and purposes everybody in different ways. The tourism industry's financial effects are thusly a critical thought in state, local and community arranging and economic improvement. Economic effects are additionally imperative factors in promoting and the executive's choices. Communities, in this manner, need to comprehend the general significance of the tourism industry to their locale, including the tourism industry's commitment to financial action in the region. (URS, 2007.)

Nonetheless, from the biological perspective the tourism industry is regularly more adequate and best than some other mechanical creation, as it is ecologically friendlier. The issue is that it is difficult to change the customary lifestyle of the nearby communities. It regularly makes pseudo clashes. Without a doubt in a few areas or nations, the elective enterprises are much more unsafe to the earth than the tourism industry. The tourism industry has the ability to influence social change. Fruitful advancement of an asset can prompt various negative effects. Among these are overdevelopment, absorption, strife, and fake reproduction. While displaying a culture to vacationers may help safeguard the way of life, it can likewise weaken or even pulverize it. The fact of the matter is to advance the tourism industry in the district so it would both give salaries and make regard for the nearby custom and culture. (URS, 2007.)

Economic effects of the tourism industry are therefore an essential thought in state, provincial and community. The effects of the tourism industry are additionally critical factors in advertising and management choices. Communities along these lines need to comprehend the general significance of the tourism industry to their area, including the tourism industry's commitment to economic movement in the region. Besides, the activities of the tourism industry include financial cost which incorporates coordinate development brought about by the tourism industry organizations, government cost for a framework to serve the vacationer, and additionally, clog and related expense borne by the person in the given locale.

Through developing position of the tourism industry in the worldwide market during the most recent few decades, as it would be normal, its developing nearness in the exploration territory has pursued likewise. In any case, as it was at that point referenced, the topic of whether the tourism industry is affecting the rate of economic development has been given clashing answers. At the end of the day, there is no reasonable or summed up a reply about the idea of connection among the tourism industry and economic development, however, there are numerous conceivable outcomes existing for more investigation.

\section{METHODOLOGY}

This study was conducted in the 3 cities of Uzbekistan. These cities have been regarded as the tourist destinations in the country.The ancient Samarkand, premier tourist attraction in Central Asia, is about 2500 years old and was center of the Silk Road connecting Europe and China. In Samarkand majority of tourists go to the Registan, one of the most spectacular architectures in Central Asia. The city was the capital of Tamerlane Empire and has various architectural heritage such as Bibi Khanymmosque,Shah-i-Zinda - the tomb of Qasim ibn Abbas ( $7^{\text {th }}$ century), Tomb of Temurids (mausoleum covered with pure gold).

The second most visited city is Bukhara, described by Curzon as 'the most interesting city in the world' (Airey and Shackley,1997) is another trade-spot in the Silk Road. The city was established around 3000 years ago. The city was the capital of the same-named empire which covered parts of modern Iran, Tajikistan, Afghanistan and it was the destination where students from all around the world came to study. The city has more than 350 monuments. The third spot is Khiva, a city enclosed with $2 \mathrm{~km}$ unbroken wall, and it was one of the significant spots in The Silk Road.

Respondents were the 97 tourists or non-residents of Uzbekistan who were present and available during the actual conduct of the survey. During the survey the researcher visited airports, hotels and some tourist destinations in the cities of Samarkand, Bukhara, and Khiva, where many tourists are visible and are concentrated, thus making sure that they will participate and be involved in the study.

The research had 97 actual respondents from the 100 target. These respondents are the Non-Uzbek tourists who were available during the conduct of the actual survey. The researcher conducted or administered the survey to the identified respondents who are willing to be involved in the study. 
Snowballing procedure or technique was adopted in the actual survey, since after one respondent had finished the survey, he/she would identify and recommend to the researcher another one, and the procedure continued until the researcher was able to get the desired number of respondents to be interviewed during that day. The researcher had to stay an average of 3 to 4 days in each city to administer the actual survey and satisfy the required number of respondents for each city.

This study endeavored to assess the quality of the tourism development in Uzbekistan. Two sets of variables have been used as variables of the study, the independent variables, and the dependent variable. The independent variables consisted of the demographic profile of the respondents in terms of their age, sex, nationality, educational attainment, income level, length of stay, purpose of visit, frequency of visit, knowledge about the tourism development, and motivation to visit. The dependent variable is the level of quality of tourism development of Uzbekistan, which will be assessed using a tool adopted from the study of Marino (2008). The assessment will be made on the quality of the 18 different attributes of tourism development using a 5-point Likert scale ( from very poor-1, to very good-5) namely: museum, architecture,Climate,Natural attraction, Tours/excursions, Transportation, Tourist information, Accommodation, Hospitality, Restaurant, Bar and Café, Night life, Cleanliness, Uncrowdedness, Shopping facility, Accessibility, Safety.

This study is both descriptive and correlational. To derive data from the respondents, it used a survey questionnaire which was personally administered by the researcher. This research is descriptive as it described the demographic profile of the respondents, after which the data on demographic profile have been correlated to the level of quality of the tourism development whether or not a significant relationship existed between them. The instrument of this study consisted of two major parts. Part 1, is a researcher-made tool consisted the demographic profile of the respondents in terms of their age, sex, nationality, educational attainment, income level, length of stay, purpose of visit, frequency of visit, knowledge about the tourism development, and the motivation to visit. Part 11 of the instrument, is the assessment on the quality of tourism development in Uzbekistan, which was adopted from the study of Marino (2008). The instrument consisted of the 18 different attributes of tourism development which were assessed using a 5-point Likert scale (very poor-1 to very good-5). These attributes are the following: Museum, Architecture, Climate, Natural attraction, Tours/excursions, Transportation, Tourist information, Accommodation, Hospitality, Restaurant, Bar and Café, Night life, Cleanliness, Uncrowdedness, Shopping facility, Accessibility, Safety, and Price.The instrument used in this study did not go through validation as the researcher relied too much on the validity of said instrument being used by Marino (2008). This study used convenience sampling in view of the very huge population. The population or the sampling frame of the study is the total tourists arrivals, specifically the foreigners or the Non-Uzbek nationalities, in the 3 cities of Uzbekistan which could not be accurately determined. The researcher decided to adopt the quota sampling, which targeted a total of 100 respondents: 34 from Samarkand City; 33 from Bukhara City ; and 33 from Khiva City. For the actual respondents only 97 participated in the survey, out of 100 . The researcher had been constrained by the time to look for other 2 respondents from Samarkand City, and another 1 from Khiva City, but Bukhara City had 100 percent retrieval rate, which means, a total of 33 participated in the survey.The data gathered with respect to the demographic profile of the respondents have been treated through the use of simple frequency and percentages. The assessment on the level of perception on the quality of tourism development in Uzbekistan, weighted mean had been used. In terms of finding out the relationship between the demographic profile of the respondents and the level of perception on the quality of tourism development in Uzbekistan, SPSS software had been used.

\section{FINDINGS AND INTERPRETATION}

This chapter presents the data gathered in the light of the objectives of the study.

\section{Demographic profile of the respondents}

Most of the respondents belong to the age range of 45 to 64 years old, constituting about 33 percent, which is indicative that tourists visiting Uzbekistan are mostly matured individuals. The youngest among the respondents is 15 years old, while the oldest is 66 years old. Majority or 67.01 percent of the respondents are male while the rest are female. This indicates that males are more inclined to travel as tourists that females. This could be attributed to the fact that travelling may pose some risks, or danger which most males could better deal with compared to females.Most of the respondents come from Russia constituting about 19.60 percent, while the least number of respondents, about only 
3 or 3.10 percent come from the United Kingdom (UK). The data indicates that Russians are more inclined to visit Uzbekistan as tourists than the rest of the nationalities. In terms of educational attainment of the respondents most or 31.96 percent of the respondents are college graduates, which indicates that the tourists visiting Uzbekistan have formal college degrees. The data further revealed that about 27.84 of the respondents have attained graduate education programs either masteral or doctoral degrees. About 21.65 percent of the respondents are high school level, while 16.49 percent have attained vocational education. There are 2 respondents belonging to the primary school level. In terms of the income of the respondents, most or 24.70 percent of the respondents have annual income bracket of $\$ 10,000$ to $\$ 19,999$; followed by the 23.70 percent having an income bracket of $\$ 5,000$ to $\$ 9,999$; while there were 15 or 15.50 percent having an income bracket of less than $\$ 5,000$ only. There were 14 respondents having an income bracket of \$20,000-29,999 and another 12 respondents having income bracket of $\$ 30,000$ to 39,999 , constituting 14.40 percent and 12.40 percent , respectively. The highest income bracket of $\$ 50,000$ and above belongs to the 4 respondent which constitute about 4.10 percent only. About 5 respondents have income bracket of 5.20 percent.In terms of their length of stay whenever they visit Uzbekistan. The data revealed that most or 33 percent of the respondents stayed for 1 week whenever they visit Uzbekistan; while 26.80 percent stayed for 2 weeks; 19.60 percent visit Uzbekistan for less than a week; $12.40 \%$ visit Uzbekistan for more than 3 weeks; while only 8 respondents stayed in Uzbekistan for 3 weeks during their visit, thus constituting about 8.20 percent.

The data implies that most of the tourists in Uzbekistan would prefer to stay in one week whenever they visit the country, enough to explore the tourist spots or popular destinations.Along the purpose of the respondents when they visit Uzbekistan. The data revealed that most or 36.10 percent visit Uzbekistan for leisure purposes; 25.80percent for business purposes; 22.70 percent having their purpose of visiting their family members and friends; about 14.40 percent visit Uzbekistan for educational purposes, while 10 respondents visit for other purposes.

This implies that most of the tourists visit Uzbekistan to leisurely spend their time and get enjoyment as they explore some of the beautiful areas or destinations in the country. In terms of their frequency of visit to Uzbekistan, The data revealed that 30.92 percent are mostly first-timers; while 28.80 percent have visit about 2 to 3 times already; 27.83 percent visited 4 to 5 times; while the other 12.37 percent have been frequently visiting Uzbekistan more than 5 times.

The data on the source of information or knowledge of the respondents about the tourism development in Uzbekistan revealed that most or 26.80 percent of the respondents derived their information from travel agencies and tour operators; 19.58 percent from recommendation from friends; another 19.58 percent from their personal knowledge about the place; 12.37 percent from promotions and advertising companies; and 10.30 percent from the internet.The data implies that tourists coming to Uzbekistan rely heavily on information that are being supplied by the travel agencies and tour operators as regards the tourism development in the country.

As regards data about the respondents' motivation to visit Uzbekistan. The data revealed that the primary motivation of most or 31.95 percent of the respondents to visit Uzbekistan focused on the tour activities being offered; 21.64 percent of respondents claimed that they are motivated to visit Uzbekistan because of its reputation; 18.55 percent of the repondents claimed that the kind of climate Uzbekistan has, is a motivating factor for them to visit the country. There were 27 respondents however, that they have varied reasons that mpotivated them to visit Uzbekistan, which constitutes about 27.83 percent.The data implies that it is the tour activities that motivated the respondents the most, to visit Uzbekistan.

\section{Assessment on the Perception of the Respondents on the quality of Tourism Development in Uzbekistan.}

Table 11 presents the data on the assessment made by the respondents based on their perception about the quality of the Tourism development in Uzbekistan. The data revealed that the overall assessment resulted to a grand mean of 3.59, which indicates that the quality of tourism development of Uzbekistan is generally good. The highest mean score derived from the assessment was that of hospitality attribute which is 4.01 , while the lowest meanscore was 3.26 which indicates that the quality of transportation facilities available for use in tourism activities had been assessed moderately by the respondents, same with that of the night life attribute which derived a mean score of 3.31. All 
the rest of attributes have been assessed as good such as the safety of the tourists when visiting Uzbekistan which derived a mean score of 3.82; then the attribute of climate with a mean score of 3.77 which is followed by the attribute of price with the mean score of 3.75; the presence of the restaurants got a mean score of 3.74; cleanliness attribute got a mean score of 3.68; architecture attribute got 3.60 mean score; natural attraction with 3.59 mean score; accommodation got a mean score of 3.58; Bar and cafés got 3.57 mean score; shopping facilities and accessibility attributes shared the same mean scores of 3.52; uncrowdedness got 3.49 mean score; Tours/excursions and museum are attributes that also got same mean scores of 3.48; while the tourist information got 3.45 mean score.

The result of the assessment implies that generally the quality of tourism development in Uzbekistan has been perceived by the respondents as good. However,

Table1. Assessment on the Perception of the Respondents on the Quality of Tourism Development in Uzbekistan

$\mathbf{n}=97$

\begin{tabular}{|l|c|c|c|c|c|c|c|}
\hline \multirow{2}{*}{ Attribute } & $\begin{array}{c}\text { Very } \\
\text { Poor }\end{array}$ & Poor & $\begin{array}{c}\text { Mode } \\
\text {-rate }\end{array}$ & Good & $\begin{array}{c}\text { Very } \\
\text { Good }\end{array}$ & $\begin{array}{c}\text { Weighted } \\
\text { mean }\end{array}$ & $\begin{array}{c}\text { Interpre- } \\
\text { tation }\end{array}$ \\
\hline Museum & $\mathbf{2}$ & $\mathbf{3}$ & $\mathbf{4}$ & $\mathbf{5}$ & & \\
\hline Architecture & 5 & 10 & 30 & 37 & 15 & 3.38 & Good \\
\hline Climate & 7 & 9 & 20 & 33 & 26 & 3.60 & Good \\
\hline Natural attraction & 8 & 11 & 19 & 34 & 25 & 3.59 & Good \\
\hline Tours/Excursions & 11 & 7 & 23 & 36 & 20 & 3.48 & Good \\
\hline Transportation & 14 & 15 & 18 & 32 & 18 & 3.25 & Moderate \\
\hline Tourist Information & 8 & 12 & 22 & 38 & 17 & 3.45 & Good \\
\hline Accomodation & 10 & 6 & 20 & 40 & 21 & 3.58 & Good \\
\hline Hospitality & 4 & 8 & 11 & 34 & 40 & 4.01 & Good \\
\hline Restaurants & 9 & 8 & 13 & 36 & 31 & 3.74 & Good \\
\hline Bars and Cafén & 8 & 7 & 24 & 38 & 20 & 3.57 & Good \\
\hline Night Life & 12 & 16 & 18 & 32 & 19 & 3.31 & Moderate \\
\hline Cleanliness & 4 & 13 & 18 & 37 & 25 & 3.68 & Good \\
\hline Uncrowdedness & 9 & 10 & 21 & 38 & 19 & 3.49 & Good \\
\hline Shoppin facilities & 7 & 8 & 28 & 36 & 18 & 3.52 & Good \\
\hline Accessibility & 8 & 10 & 22 & 38 & 19 & 3.52 & Good \\
\hline Safety & 4 & 11 & 15 & 35 & 32 & 3.82 & Good \\
\hline Price & 8 & 10 & 12 & 35 & 32 & 3.75 & Good \\
\hline Grand Mean & & & & & & 3.59 & Good \\
\hline & & & & & & & \\
\hline
\end{tabular}

Weight
1
2
3
4
5

Score

$(1.00-1.80)$

$(1.81-2.60)$

(2.61-3.40)

$(3.41-4.20)$

(4.21-5.00)
Interpretation

Very poor quality

Poor quality

Moderate quality

Good quality

Very good quality

the assessment further points out that the kind of transportation facilities being provided to the tourists visiting Uzbekistan is a concern that the government of uzbekistan should give relevant focus. Night life as most of activities that tourists would want to have during their visit, is also another concern that need to be addressed to. 


\section{Hypotheses testing}

The hypotheses whether the demographic profile of the respondents have no significant relationship on the level of perceptions among respondents on their assessment on the quality of tourism development in Uzbekistan have been tested at 0.05 level of significance, and the results are presented in Table 2.

Table 2. Summary Table on the Chi-Square Test Results on the Relationship Between Demographic Profile of the Respondents and the Level ofperception on the Assessment on the Quality of Tourism Development in Uzbekistan

\begin{tabular}{|l|l|c|c|c|c|c|c|c|c|c|}
\hline \multicolumn{1}{|c|}{ variable } & Attribute & $\mathbf{p}$ & attribute & $\mathbf{p}$ & attribute & $\mathbf{p}$ & attribute & $\mathbf{p}$ & aatribute & $\mathbf{p}$ \\
\hline Age & Transport & 0.002 & Accomodation & 0.009 & Nightlife & 0.05 & $\begin{array}{l}\text { Uncrow- } \\
\text { dedness }\end{array}$ & 0.049 & & \\
\hline Gender & $\begin{array}{l}\text { Tourism } \\
\text { information }\end{array}$ & 0.045 & safety & 0.019 & & & & & & \\
\hline Nationality & Architecture & 0.007 & accomodation & 0.018 & $\begin{array}{l}\text { Natural } \\
\text { attraction }\end{array}$ & 0.01 & Restaurant & 0.001 & cleanliness & 0.019 \\
\hline $\begin{array}{l}\text { Length of } \\
\text { stay }\end{array}$ & shopping & 0.014 & Night life & 0.039 & & & & & & \\
\hline $\begin{array}{l}\text { Purpose of } \\
\text { visit }\end{array}$ & climate & 0.015 & & & & & & & & \\
\hline $\begin{array}{l}\text { Frequency of } \\
\text { visit }\end{array}$ & hospitality & 0.021 & & & & & & & & \\
\hline $\begin{array}{l}\text { Source of } \\
\text { knowledge }\end{array}$ & Architecture & 0.012 & Museum & 0.047 & & & & & & \\
\hline Motivation & Restaurant & 0.018 & & & & & & & & \\
\hline
\end{tabular}

At 0.05 level of significance, the chi square test revealed that the age, gender, nationality, length of stay, purpose of visit, frequency of visit, source of information, motivation to visit are significantly related, while education, and income are not.

H1-1.Age of the respondent is significantly related to the level of perception on the quality of tourism development in Uzbekistan in terms of transportation(.002), accommodation, nightlife, and uncrowdedness. However, the other attributes have no statistically significance in the relation with the category of Age.

H1-2. Gender of the respondent is significantly related to the level of perception on the quality of tourism development in Uzbekistan in terms of tourism information and safety, but the other attributes have no statistically significance in the correlation with the category of Sex.

H1-3. The nationality of the respondent is significantly related to the level of perception on the quality of tourism development in Uzbekistan in terms of architecture, accommodation, natural attraction, restaurant, and cleanness. Nevertheless, this category has no statistical significance in the correlation of the other attributes.

H1-4. Educational attainment of the respondent does not have any statistical significance in terms of relation with the attributes.

H1-5. The income level of the respondent did not show any statistical significance in terms of relation with the attributes.

H1-6. Length of stay of the respondent showed the statistical significance in the relation with the attributes such as shopping and nightlife.

H1-7. Purpose of the visit of the respondent is significantly related to the level of perception on the quality of tourism development in Uzbekistan only in terms of climate, but it is not statistically significant in the relation with the other attributes.

H1-8. The frequency of visit of the respondent showed the statistical significance in the relation with the attribute of hospitality. However, this variable is not significantly related to the other attributes. 
H1-9. Source of knowledge about Uzbekistan of the respondent has statistical significance in the relation with the attributes such as architecture and museum.

H1-10.. The variable motivation to visit Uzbekistan showed no statistical significance in the relation with the attributes but restaurant only.

\section{CONCLUSION AND RECOMMENDATION}

\section{Conclusion}

The study concluded that in terms of demographic profile of the respondents, most of them belonged to 45 to 64 age bracket, with 15 years old as the youngest and 66 years old as the oldest. Majority of the respondents are males, mostly Russians, Indians and Japanese. Most of the respondents are college graduates, with annual income ranging from US\$10,000 to 19,000; and preferred to stay for one week whenever they visit Uzbekistan for leisure purposes. Most of the respondents are first timers in Uzbekistan, and they were motivated to visit the country in view of the many tour activities being offered. The respondents claimed that the source of information that prompted them to visit Uzbekistan came from the travel agencies and tour operators.

As regards assessment made by the respondents on the level of perception on the quality of tourism development in Uzbekistan, the result revealed as generally good (grand mean of 3.59). However, the assessment further pointed out that the kind of transportation facilities being provided to the tourists visiting Uzbekistan is a concern that the government of Uzbekistan should give relevant focus. Night life as most of activities that tourists would want to have during their visit, is also another concern that need to be addressed to.

In finding out whether a significant relationship existed between the demographic profile of the respondents and their level of perception on the quality of tourism development in Uzbekistan, at 0.05 level of significance, the chi square test revealed that the age, gender, nationality, length of stay, purpose of visit, frequency of visit, source of information, motivation are significantly related, while education, income and price are not.

\section{Recommendations}

In the light of the findings derived from this study, the researcher would like to advance this recommendations:

1. The government agency whose mandate is to develop, improve and sustain tourism development in Uzbekistan, must direct their focus towards improving the quality of transportation facilities and the relevant activities offered at night among tourists.

2. The tourism sector of Uzbekistan must also develop and promote some tourism programs among the youth, so as to increase the presence of younger tourists.

3. Promotional campaigns about the tourism industry of Uzbekistan must be strengthened more and utilized social media platforms.

4. More research studies about tourism industry which will put emphasis on the economic valuation of some tourist spots and popular destinations.

5. A research could be conducted in other areas outside Uzbekistan to support or negate the findings derived from this study.

\section{REFERENCES}

[1] Agnew, M.D. and Viner D.( 2001) Potential Impacts of Climate Change on International Tourism. Tourism and Hospitality Research. Volume 3, Issue 1, pp.37-60 Available at https://doi.org/10.1177/146735840100300104

[2] Airey and Shackley (1997)“Tourism Development in Uzbekistan”. Tourism Management, Vol.18,4. Pp 199-208

[3] Al-Ababneh, M. (2013). Service quality and its impact on tourist satisfaction. Interdisciplinary Journal of Contemporary Research in Business 4(11): 164-176.

[4] Ateljevic,J.\& Page, S.J 2009. Tourism and entrepreneurship. International perspective. e-book. 
[5] Chen, C.F. \& Tsai, D.C. 2007. How destination image and evaluative factor affect behavioural intentions. Tourism Management 28(4). 1115-1122.

[6] Chon, K.S. (1991). Tourism destination image modification process: Marketing implication. Tourism management, 12(1), 68-72.

[7] Coulibaly, S., Deichmann, U., Dillinger, W. R., Ionescu-Heroiu, M., Kessides, I. N., Kunaka, C., \&Saslavsky, D. (2012). Eurasian Cities: New Realities along the Silk Road. World Bank Publications.

[8] Fakeye,P.C\&Crompton,J.L (1991). Image difference between prospective, first-time and repeat visitors to the Lower Rio Grande Valley. Journal of Travel Research, 30(2), 10-16.

[9] Gallarza, M.G., Saura, I.G. \& Moreno, F.A. 2013. The quality-value-satisfaction-loyalty chain: relationships and impacts. Tourism Review 68(1), 3-20.

[10] Gallego,S.M., Rodríguez, F.L., \& Rodríguez, J.P. (2011). "Tourism and trade in OECD countries. A dynamic heterogeneous panel data analysis," Empirical Economics, Springer, vol. 41(2), pages 533-554, October.

[11] Godfrey, K., and Clarke, J. (2000). The tourism development handbook: a practical approach to planning and marketing. London: Continuum

[12] Golisheva, E.V. (2012): "Improvement in tourism development organization and regulation mechanism under market conditions". Tashkent. PhD, pp.3-15

[13] Horák, S. (2014). Visa regimes and regulatory documents as an obstacle for tourism development in Central Asia. In: Tourism in Central Asia: Issues and Challenges (Uysal, M. - Kantarci, K. - Magnini, V. P., eds.). Apple Academic Press, Waretown, NJ, 2014, p. 233-258. ISBN 978-1771880558.

[14] Jang, S \& Feng, R. (2007). Temporal destination revisit intention: The effects of novelty seeking and satisfaction. Tourism Management.(28),580-590

[15] Kantarchi K. (2007). "Perceptions of foreign investors on the tourism market in central asia including Kyrgyzstan, Kazakhstan , Uzbekistan and Turkmenistan”. Tourism management 28(3), 820-829.

[16] Kantarci K., Uysal,M. andMagnini, V. (2014). Tourism In Central Asia , 1st Edition, New York. Apple Academic Press. Available at https://www.taylorfrancis.com/books/e/9780429153761

[17] Kozak, M. (2001). "Repeaters' behaviour at two distinct destinations". Annals of Tourism Research, 28 (3), 784-807.

[18] Kozak, K. \&Remmington, M. (2000). Tourist satisfaction with Mallorca Spain, as an off-season holiday destination. Journal of Travel Research 38, 260-269.

[19] Lee, C., Kang, S., Reisinger, Y. and Kim, N. (2012), “Incongruence in destination image: central Asia region", Tourism Geographies: An international Journal of Tourism Space, Place and Environment, Vol. 14 No. 4, pp. 599-624.

[20] Marino, E.D. (2008) The Strategic Dimension of Destination Image: An Analysis of the French Riviera Image from the Italian Tourists Perceptions. Available at https://pdfs.semanticscholar.org/e0ee/73f196e1ea2f6d0099ffe0951b0309099d25.pdf?_ga=2.173685859.17 35874607.1574250496-1499951109.1574250496

[21] Morrison,A., Rimmington,M. \&Williams,C. (1999). Entrepreneurship in hospitality. Tourism and leisure industries. e-book.

[22] Phelps,A.(1986). 'Holiday destination image - The problem of assessment: an example developed in Menorca'. Tourism management,7(3), 168-180.

[23] Pizam, A. \& Ellis, T. (1999). Customer satisfaction and its measurement in hospitality enterprises. International Journal of Contemporary Hospitality Management, 11(7), 326-339.

[24] Prayag, G. (2009). Visitors to Mauritius - Place, Perceptions and Determinants of Repeat Visitation (Thesis, Doctor of Philosophy (PhD)). The University of Waikato, Hamilton, New Zealand. Avaialable at https://hdl.handle.net/10289/3975

[25] Price V. and Tewksbury D. (1997) "News values and public opinion: A theoretical account of media priming and framing", Progress in Communication Ssciences, 45.2, pp.173-212

[26] Ramseook-Munhurrun, P., Seebaluck, N.V. \& Naidoo, P. (2015). Examining the structural relationships of destination image, perceived value, tourist satisfaction and loyalty: case of Mauritius. Procedia - Social and Behavioral Sciences 175(15), 252-259

[27] Ryu, K., Han, H. \& Kim, T.H. (2008). The relationships among overall quick-casual restaurant image, perceived value, customer satisfaction, and behavioral intentions. International Journal of Hospitality Management 27(8), 459-469. 
[28] Salleh, M., Omar, K. \&Yaakop, A.Y. (2013). Tourist Satisfaction. International Journal of Business and Social Science 4(5), 221-226.

[29] Tang, Chor Foon \& Abosedra, Salah. (2012). Small Sample Evidence on the Tourism-led Growth Hypothesis in Lebanon. Current Issues in Tourism. 17. 234-246. 10.1080/13683500.2012.732044.

[30] United Nations World Tourism Organization ( 2013) https://www2.unwto.org/publication/unwto-annualreport-2013

[31] URS Australia Pty.Ltd (200). Assessing the value of coast to Victoria. Available at http://www.vcc.vic.gov.au/publications/AssessingtheValueoftheCoasttoVictoria.p

[32] Vroom, V. H. (1964). Work and motivation. 331 p. Carnegie Institute of Technology, Pittsburg, PA.

[33] World Tourism and Travel Council, 2018). Available at http://www.iosrjournals.org/iosrjbm/papers/Vol21-issue3/Series-5/D2103052324.pdf

[34] World Tourism and Travel Council. Economic Impact 2018). Available at http://d.researchbib.com/f/ajMJHhnKAgLF5fqv9cp3A1MKZiEHHjAQNkYmRjK0ISZQDjZI9VLJkcoT9 2K0EynUEdLKWyYaOxMt.pdf

[35] World Scientific News, (2017). available at http://www.worldscientificnews.com/wpcontent/uploads/2017/08/WSN-863-2017-134-149.pdf

[36] Xu, g. (2013). Research on China`s Cruise Tourism. Special Economic Zone, 9, 104-106

[37] Yoon, Y. \&Uysal, M. (2005). An examination of the effects of motivation and satisfaction on destination loyalty: structural model. Tourism Management 26(1), 45-56.

[38] Zabkar, V., Brencic, M.M. \&Dmitrovic, T. (2010). Modelling perceived quality, visitor satisfaction and behavioral intentions at destination level. Tourism Management 31(4),537-546.

\section{AUTHOR'S BIOGRAPHY}

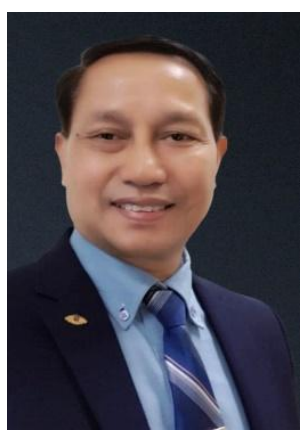

ASTERIO T. MIRANDA, JR. is a faculty member of the College of Business Administration of Keimyung University(KMU), South Korea. He Holds a doctorate degree in Extension Education, with Agribusiness Management as cognate, from the University of the Philippines at Los Banos (UPLB), Laguna, Philippines. Prior to his teaching job in KMU, he was Associate Professor of the Catholic University of Daegu, South Korea for $31 / 2$ years. Before his stint in South Korea, he was also Associate Professor and Chair of the Department of Agribusiness and Agricultural Economics of the College of Agriculture, Fisheries and Natural Resources, University of Eastern Philippines (UEP), University Town, Northern Samar. Later, he was designated as Technical Assistant on Finance to the University President. Dr. Miranda was a scholar of UEP under Plan-C of the UEP Faculty Development Program from 1995 to 1996 while pursuing his master's degree in Business Administration at the Graduate School, UEP For his Doctorate degree, he was awarded full scholarship by the Department of Agriculture-Bureau of Agricultural Research (DA-BAR) under the NARDSAF, from 2002 to 2004.During his teaching stint UEP, he received Award of Distinction for Teaching Excellence for several times. From February 2008 to January, 2009 he was tapped by the World Council for Credit Union as one of its Technical Advisors of a project in Southern Afghanistan which was tasked to organize and develop Islamic Investment and Finance Cooperatives, under the auspices of USAID. He extends consultancy services to cooperatives and non-government organizations in the Visayas Region, Philippines.

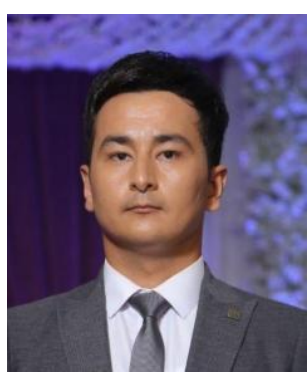

ADHAM ISRAILOV is a faculty member of the Yeoju Technical Institute in Tashkent, Tashkent City, Uzbekistan. He holds a Master's Degree in Business Administration, from the Keimyung University, under the Global MBA program, as scholar.He took his Bachelor's degree in English Language and Literature from Uzbekistan World Languages University. He was a former Primary school teacher handling English subjects. At present, he handles Tourism, Marketing and Management courses at the undergraduate level in the institute where he is connected. He is more inclined to doing research along the areas of tourism, business and entrepreneurial management. 


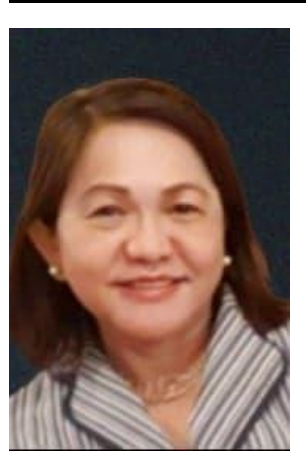

JUNETH LOURDES FIEL-MIRANDA is an associate professor of accounting and other business related subjects at Keimyung Adams College (KAC) of the Keimyung University in South Korea. She has been an associate professor at the Catholic University of Daegu, South Korea, teaching accounting courses. She graduated with distinction from Western Leyte College for her undergraduate degree in Commerce, and received her Master in Business Administration (MBA) degree from the University of Eastern Philippines, and finished her Doctorate degree in Management major in Human Resources Management at the University of San Jose Recoletos, Cebu City, Philippines. She successfully hurdled the Professional Board Examination for Certified Public Accountants (CPA). For over two decades, she worked as Associate Professor of accounting and other business related courses at the University of Eastern Philippines, and was involved in the development and implementation of the four-year degree program in cooperatives; conducted research and extension activities; and took an active role in the establishment of a collaborative linkage between the University of Eastern Philippines and the Grameen Foundation-Australia. She has been a consultant in the areas of management, systems designing and operations of the different business organizations, cooperatives and non-government organizations in the Philippines. She is currently the president, and one of the pioneers of a nationwide micro-finance institution-the FundacionGrameenPilipinas (FGP), which helps students from the less-advantaged sectors of society through microcredit schemes.

Citation: Adham Israilov, et.al.,. “ The Tourism Development in Uzbekistan: An Assessment" International Journal of Managerial Studies and Research (IJMSR), vol 8, no. 8, 2020, pp. 95-110. doi: https://doi.org/10.20431/2349-0349.0808010.

Copyright: (C) 2020 Authors. This is an open-access article distributed under the terms of the Creative Commons Attribution License, which permits unrestricted use, distribution, and reproduction in any medium, provided the original author and source are credited. 